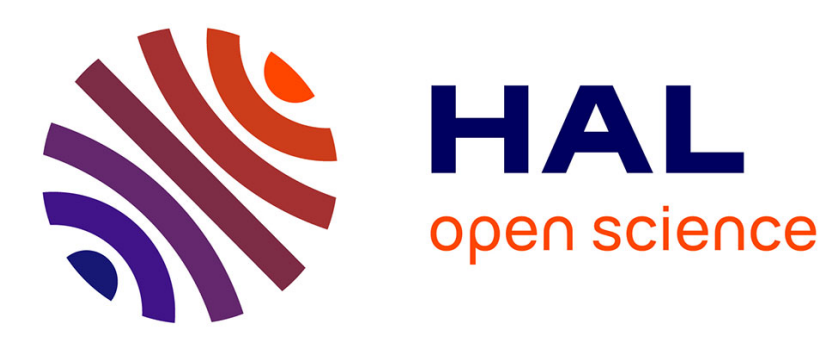

\title{
Development and Validation of a Scale Assessing Test Anxiety in Physical Education
}

\author{
Sarah Danthony, Nicolas Mascret, François Cury
}

\section{To cite this version:}

Sarah Danthony, Nicolas Mascret, François Cury. Development and Validation of a Scale Assessing Test Anxiety in Physical Education. Journal of Teaching in Physical Education, 2019, 38 (4), pp.357366. 10.1123/jtpe.2018-0282 . hal-02462101

\section{HAL Id: hal-02462101 https://hal-amu.archives-ouvertes.fr/hal-02462101}

Submitted on 4 Feb 2020

HAL is a multi-disciplinary open access archive for the deposit and dissemination of scientific research documents, whether they are published or not. The documents may come from teaching and research institutions in France or abroad, or from public or private research centers.
L'archive ouverte pluridisciplinaire HAL, est destinée au dépôt et à la diffusion de documents scientifiques de niveau recherche, publiés ou non, émanant des établissements d'enseignement et de recherche français ou étrangers, des laboratoires publics ou privés. 
Development and validation of a scale assessing test anxiety in Physical Education

Journal of Teaching in Physical Education

Sarah Danthony ${ }^{\mathrm{a}}$, Nicolas Mascret ${ }^{\mathrm{a}, \mathrm{b} *}, \&$ François Cury ${ }^{\mathrm{a}}$

${ }^{a}$ Aix Marseille Univ, CNRS, ISM, Marseille, France

${ }^{b}$ SFERE-Provence, FED 4238, Marseille, France

*Corresponding author

Nicolas Mascret

Institute of Movement Science, 163 avenue de Luminy, Case 910, 13288 Marseille cedex 9, France

Email: nicolas.mascret@univ-amu.fr

Date of submission: February 28, 2019

The authors report no conflicts of interest. 


\begin{abstract}
Purpose: There is currently no scale assessing test anxiety in PE despite the specificities of this class (e.g., body image, failure in front of peers). Accordingly, the aim of the present study was to develop a specific scale named the "Revised Test Anxiety and Regulatory dimension of anxiety in Physical Education scale" (RTAR-PE). Method: Self-report data were collected from 281 (Study 1) and 390 (Study 2) students in French schools (ages 13-18).

Results: Study 1 showed that the RTAR-PE scale has acceptable psychometric properties. Study 2 confirmed the results of Study 1 and also showed the convergent, discriminant, and predictive validities of the scale. Gender differences were found, with girls showing higher PE test anxiety than boys.

Discussion/Conclusion: The RTAR-PE is a newly available scale assessing the different facets of test anxiety in PE (worry, self-focus, bodily symptoms, somatic tension, perceived control) considering the specificities of this class.

Keywords: evaluation, achievement goals, regulatory dimension of anxiety, education, perceived competence, perceived control
\end{abstract}


Development and Validation of a Scale Assessing Test Anxiety in Physical Education

\section{Introduction}

Evaluations, tests, and examinations are an inevitable part of students' lives. Although they may provide academic recognition at the end of the learning process, they also represent a threatening situation and a significant source of worry and anxiety (Putwain, Connors, \& Symes, 2010), with numerous individual differences among students. The existing scales (e.g., Benson \& El-Zahhar, 1994; Spielberger, 1980) assess test anxiety in general regardless of the school discipline and its potential specificities, as may be the case for physical education (PE). PE is often considered an enjoyable and fun class by a significant proportion of students (especially compared with other classes), but many other students may also consider participating in a PE class particularly stress-inducing (Barkoukis, Tsorbatzoudis, Grouios, \& Rodafinos, 2005). Anxiety during PE lessons has been researched in numerous studies. For example, endorsing an entity theory in PE (i.e., considering ability stable and innate) positively predicted anxiety in PE (Ommundsen, 2001), and state anxiety was negatively related to enjoyment in PE (Yli-Piipari, Watt, Jaakkola, Liukkonen, \& Nurmi, 2009). But, to date, anxiety during PE tests has not been specifically studied and no measure of test anxiety in PE has been available. The aim of the present research is to develop and validate a scale to assess specifically test anxiety in PE.

\section{Assessing Test Anxiety}

Perception of examinations and other assessment situations as threatening leads to test anxiety (Spielberger \& Vagg, 1995). While early studies defined test anxiety as a unidimensional attribute (i.e., Sarason, 1961), test anxiety quickly became a multidimensional construct consisting, in the literature, of a cognitive component and an 
affective-physiological component (Liebert \& Morris, 1967). The cognitive component called "worry" is related to negative thoughts especially about failure; the affectivephysiological component called "emotionality" is related to perception of physiological responses. Appropriate methods of measuring test anxiety immediately became a major subject of research and led to the validation of several instruments. To capture the two components of test anxiety, Spielberger (1980) developed the Test Anxiety Inventory (TAI), which is to date the most widely used instrument to assess test anxiety. But this scale is still contested because the worry and emotionality dimensions strongly overlap and the internal consistency of the worry subscale is low (Zeidner, 2007). Other scales have been validated, such as the Cognitive Anxiety Scale (Cassady \& Johnson, 2002), which omits the emotionality component of test anxiety. Addressing these considerations, Sarason (1984), with the Reactions to Tests (RTT) scale, and then Benson and El-Zahhar (1994), with the Revised Test Anxiety (RTA) scale, separated the cognitive dimension in worry (thoughts related to failure) and test-irrelevant thinking (distracting thoughts), and the affective-physiological dimension in somatic tension (general autonomic arousal, like nervousness) and bodily symptoms (specific physiological effects, like headache). Construct validity and reliability of the four-factor RTA scale have been reported in numerous studies (e.g., Benson et El-Zahhar, 1994; Hagtvet \& Benson, 1997).

This scale seems particularly relevant to assess test anxiety in PE, since tension and bodily symptoms are valuable subscales of the RTA scale for studying the affective-physiological component of anxiety during PE tests. Indeed, they are related to the motor dimension of PE, the most important specificity of this class. But the initial formulation of these items (e.g., "During tests, I have difficulty breathing”) is problematic in the PE context. The physical performance involved in PE leads 
systematically to somatic tension and bodily symptoms, whether during tests or during lessons. For example, students automatically have difficulty in breathing or very tight muscles when they practice middle-distance running in PE lessons. Comparing bodily symptoms and somatic tension during PE tests with those experienced during PE lessons may be a promising way to specifically assess PE test anxiety in its affectivephysiological component. Consequently, a rewording of the initial items of the RTA scale is necessary to really assess PE test anxiety (e.g., "During PE tests, I have more difficulty breathing than during PE lessons"). This is the first argument for the need to develop a specific scale to assess PE test anxiety through its worry and emotionality components. But an additional component may also be investigated.

The theoretical framework of anxiety often includes more components than worry and emotionality so as to better understand the complexity and multidimensionality of anxiety (e.g., Hagtvet \& Benson, 1997). A construct has recently been added to the conventional cognitive and somatic components of anxiety to assess the regulatory dimension of anxiety, explicitly indicating an adaptive potential of anxiety, first highlighted in the sport context (Cheng, Hardy, \& Markland, 2009). The regulatory dimension of anxiety, reflected by the component of perceived control, measures the capacity to cope and achieve the purpose of the task under pressure (Cheng \& Hardy, 2016). This positive dimension of anxiety seems relevant in the test anxiety domain because anxious students evaluate not only the cognitive and the somatic anxiety induced by tests but also their capacities to cope with these two forms of anxiety (Cheng et al., 2009) and to pass the test. High perceived control may explain why students succeed in tests despite cognitive and affective-physiological anxiety. This construct may be added to the worry and emotionality components of test anxiety for a better understanding of this phenomenon. 
All the scales mentioned above assess test anxiety in general regardless of the school discipline. But the educational literature has developed different anxiety scales for lessons in specific subjects - e.g., mathematics (Meece, Wigfield, \& Eccles, 1990), learning a foreign language (Sanchez-Herrero \& Sanchez, 1992), or PE (Barkoukis et al., 2005). Moreover, domain-specific scales used during lessons have better predictive validity than general measures (Smith, Schutz, Smoll, \& Ptacek, 1995). By contrast, test anxiety is usually conceptualized in a trait-like fashion and self-report questionnaires for assessing test anxiety evaluate it in a general way. While these scales may instruct students to evaluate their test anxiety in a specific school discipline with an introductory text, the whole questionnaire is always the same. The specificities of each school discipline are not included either in the wording of items or in the items selected. However, some school disciplines, such as PE, could lead to a specific form of test anxiety.

\section{Anxiety and Test Anxiety in PE}

Studying test anxiety in PE is relevant because it merges anxiety induced by tests and anxiety induced by the specificities of PE. PE combines both sport and educational elements (Barkoukis et al., 2005, Warburton \& Spray, 2017). It aims for example to develop movement skills (based on sport activities), to develop educational skills (e.g., cooperation, fair play, strategy, emotion regulation), to give the students positive affective experiences which will encourage them to get involved in physical activity outside the school, and to increase self-esteem (Walling \& Duda, 1995). We propose that test anxiety in PE refers to an unpleasant emotional state in reaction to perceived threat concerning the scheduled and rated performance of a test or an exam at the end of the learning process. For example, a demonstration of a task in front of the class during PE lessons does not lead to test anxiety, whereas performing the same task 
at the end of the learning process with a corresponding grade leads to test anxiety. In general, high-stakes examinations represent a significant source of worry and anxiety for students (Putwain, Connors, et al., 2010), because of fear of failure, negative evaluation from others, and threats to esteem/position (Spielberger \& Vagg, 1995; Zeidner, 2007).

In this vein, the specific context of PE is particularly stress-inducing because students are evaluated both by the teacher and their classmates. Performing the evaluative motor task in front of other students often leads to social pressure which can cause negative affective experiences and anxiety (Liukkonnen, Barkoukis, Watt, \& Jaakkola, 2010; Yli-Piipari et al., 2009), since fears of evaluation, public competition, failure, or body image are important threats to students' self-esteem (Barkoukis, Rodafinos, Koidou, \& Tsorbatzoudis, 2012). This is particularly true for adolescents who have a degraded body image (Siegel, Yancey, Aneshensel, \& Schuler, 1999). Moreover, the results of examination performance in PE are immediately available and known to all, whereas their performance in (for example) math tests is often delayed and private (Barkoukis et al., 2005). This public nature of competence in PE (Warburton, 2017) may be particularly stressful during evaluations and examinations. Test anxiety may also be triggered by parents who want their children to achieve the best school grades. While being physically active is socially recognized as beneficial, receiving a bad grade or the risk of failing a PE exam are supplementary forms of social-evaluation anxiety in PE that can be added to the anxiety already experienced during lessons (Barkoukis et al., 2005). While the specificities of PE often lead to anxiety for students with low motor skills, and even for highly skilled students (Liukkonnen et al., 2010), no studies have been conducted hitherto to specifically 
investigate PE test anxiety. To this end, the development and validation of a specific scale assessing PE test anxiety may be relevant for developing research in this area.

All the previous considerations seem to apply particularly in the French PE context. Students are frequently faced with PE examinations leading to grades and/or judgments (between three and eight times each year). Their PE grades contribute to the evaluation of their school year and to the national qualifications obtained at the end of the collège (ages 13-15) and the lycée (ages 15-18). For the baccalauréat (national certificate at the end of the lycée), students are evaluated simultaneously with their classmates by two PE teachers (their own teacher and another one whom they may not know). The results of PE examinations in France show that girls have mainly lower grades than boys. All these elements might cause French students, especially girls, to be particularly anxious during PE examinations. However, in some countries assessment in PE is minimal despite recommendations for its inclusion. For example, fitness-based tests are the most common form of assessment in the United States, and they are often not included in students' course grades. In other contexts, grades may also be only dependent on PE participation. Test anxiety may indeed be reduced in these contexts. But this does not mean that test anxiety is absent. Cross-cultural studies may be a promising way to investigate this question, but the first step is to create a scale assessing test anxiety and to validate it in a potentially stressful evaluative context, such as the French PE context. But the existing scales assess anxiety PE, and not specifically test anxiety.

Only a very limited number of studies have investigated the assessment of anxiety with scales adapted to the specificities of PE. Barkoukis et al. (2012) have validated the Physical Education Trait Anxiety Scale (PETAS) based on a three-factor structure (somatic anxiety, worry, and cognitive processes). The traditional components 
of anxiety (cognitive and somatic) are assessed, but cognitive anxiety is split into two subscales. Worry corresponds to negative expectations from involvement in the activity, and cognitive processes correspond to attention, cognition, thought, memory, and problem solving during the tasks that cause anxiety (Barkoukis et al., 2012). This scale is interesting in the PE context because it measures both the learning process and the competitive and evaluative aspects of PE classes. Barkoukis et al. (2005) also developed a measure of state anxiety in PE, the Physical Education State Anxiety Scale (PESAS). This scale assesses the basic anxiety dimensions (cognitive and somatic) and the related cognitive processes that interfere with the experience of anxiety. The PESAS is used to describe the experience of anxiety just before a stressful event in PE. According to the authors, the cognitive processes assessed by the two state and trait anxiety scales measure especially the symptoms of anxiety associated with the learning process during PE lessons, not with test anxiety. To date, there is no specific scale which measures anxiety in PE during tests, evaluations, or exams. Moreover, Barkoukis et al. (2005) declared that PE lessons may be as stressful as tests in other school disciplines such as math. But what about anxiety during tests in PE? And what about the potential correlates of PE test anxiety?

Test anxiety has been related to several constructs in the general test anxiety literature. Concerning the relationships between mastery-approach goals (i.e., doing well relative to task demands or one's own performance trajectory), performanceapproach goals (i.e., doing well relative to others), mastery-avoidance goals (i.e., not doing poorly relative to the task demands or one's own performance trajectory), performance-avoidance goals (i.e., not doing poorly relative to others), and general test anxiety, mastery-avoidance, performance-approach, and performance-avoidance goals were often positively correlated with worry, somatic tension, and bodily symptoms 
(Putwain \& Symes, 2012). Although the results were more contrasted for performanceapproach goals, avoidance-based goals are positively related to test anxiety (Elliot \& McGregor, 2001). All the previous studies are based on test anxiety in general; hence, there is a need to test whether the same patterns are confirmed or not in the specific context of test anxiety in PE. We may hypothesize that avoidance-based goals would also be positively correlated with worry, self-focus, bodily symptoms, and somatic tension because, in the PE context as in the sport context, avoidance-based goals have less adaptive effects on young people's cognitions, affect and behavior than approachbased goals (e.g., Mascret, Elliot, \& Cury, 2015; Warburton, 2017).

Furthermore, perceived academic competence was negatively related to two components of test anxiety, namely worry and somatic tension (Putwain, Woods, \& Symes, 2010) and girls have higher test anxiety than boys (Putwain, Woods, et al., 2010). All these results from the general test anxiety literature need to be confirmed in the PE context, but a different pattern could also be found with a higher potential impact on PE test anxiety of the physiological-affective components of anxiety (i.e., bodily symptoms and somatic tension) due to the motor and bodily specificities of PE. Finally, tension, effort, and enjoyment in PE have never been studied in relation with general test anxiety. But these constructs are also relevant to include in the present study since tension is a form of anxiety during PE lessons, effort in PE is negatively related to somatic and cognitive dimensions of PE anxiety (Liukkonnen et al., 2010), and enjoyment during PE lessons is negatively related to state anxiety (Yli-Piipari et al., 2009). Consequently, they may be related positively (tension) and negatively (perceived competence and enjoyment) to the negative components of PE test anxiety (worry, selffocus, bodily symptoms, somatic tension) and inversely correlated with the positive component of PE test anxiety (perceived control). All these hypotheses need to be 
tested, and the results may be relevant for a better understanding of test anxiety in the PE context.

\section{The Present Study}

Over the past 50 or more years, general test anxiety has been an important focus of research and has been related to numerous constructs (e.g., achievement goals, perceived competence). Several questionnaires (e.g., RTA, TAI) have also been validated to assess it. But to date no studies have been conducted in the PE context and no specific scales have been validated to measure PE test anxiety. However, the specificities of tests, evaluations, and examinations in PE (e.g., fear of failure in front of peers, competition, public nature of competence, body image) suggest the need for a specific scale. Consequently, the first purpose (Study 1) was to develop and validate a scale assessing the different dimensions of test anxiety in PE (worry, self-focus, bodily symptoms, somatic tension, perceived control), evidencing potential gender differences. The second purpose (Study 2) was to investigate the predictive validity of this scale with constructs known to be associated with test anxiety and/or PE anxiety.

\section{Study 1}

The aims of Study 1 were (a) to develop a preliminary version of a test anxiety scale in PE, (b) to select the most appropriate items, (c) to test the factorial structure of the scale which was created, and (d) to highlight potential gender differences.

\section{Method}

Participants. A preliminary version of the scale was administered to a sample of 281 students ( 127 boys, 146 girls, 8 missing data; $M_{\text {age }}=15.53$ years, $S D=1.75$; age range 12-19) from several French collèges (ages 13-15, 90 students, 68.89\% girls) and lycées (ages 15-18, 191 students, 42.93\% girls) in the south of France. 
Procedure and measure development. This study was first approved by the Chief Education Officer of the Académie of Aix-Marseille and by the schools' principals. The participants completed the preliminary questionnaire at the beginning of regular PE courses, on a day without PE evaluations or exams. They were told that their responses would remain anonymous, would not be shown to their PE teacher, and would not influence their course grade. The class teacher and the two first authors of the study supervised the procedure, which lasted approximately 10 minutes. Students did not ask specific questions and they did not return to the researchers signed parental forms prohibiting them from participating in the study.

The construction phase of the preliminary version of the scale involved creating the initial item pool (Weiss, Bolter, \& Kipp, 2014). First, items from some subscales of Benson and El-Zahhar's (1994) RTA scale were included in the preliminary version of the questionnaire, assessing worry (thoughts related to failure), somatic tension (general autonomic arousal, like nervousness), and bodily symptoms (specific physiological effects, like headache).

Secondly, the items assessing somatic tension and bodily symptoms were all reformulated. As seen previously, the initial formulation of these items of the original RTA scale was not adapted to assess test anxiety in the specific PE context because somatic tension and bodily symptoms were always present in PE in relation to the physiological consequences of physical activity. Consequently, the items were reworded to differentiate anxiety during PE lessons from test anxiety (e.g., "During tests I feel tense” was replaced by "During PE tests, I feel more tense than during PE lessons"). Items from the worry subscale of the initial RTA scale were maintained in their existing version. 
Thirdly, one of the subscales of the initial RTA scale (test-irrelevant thinking) was not particularly adapted to PE, because it is difficult to have distracting thoughts such as daydreaming about a forthcoming holiday (Putwain \& Symes, 2012) during an evaluative motor task with strong time constraints. But the cognitive dimension of anxiety is not limited to test-irrelevant thinking in the literature. The additional component of self-focus is very interesting to include in the cognitive dimension of anxiety in the PE context, since self-focus increases awareness of shortcomings concerning the performance of a stressful task (Cheng \& Hardy, 2016). In addition, several items of the self-focus subscale of Cheng et al.'s (2009) three-dimensional model of performance anxiety are based on fear of the judgment of others, which we have identified as a key component of anxiety during PE lessons and probably during tests. Consequently, we adapted the items of the self-focus subscale of Cheng et al.'s (2009) scale to the specificities of PE and test anxiety (e.g., "I am conscious that others will judge my performance" was replaced with "During PE tests, I am conscious that other students will judge my performance negatively”).

Fourthly, the regulatory dimension of anxiety, represented by perceived control, was also included in the preliminary version of the scale. Based on the initial work of Cheng et al. (2009) on performance anxiety in the sport domain, this positive dimension of anxiety was included in the tested questionnaire, replacing "performance" with "good grade." This subscale was used in the scale under development with the introductory sentence: "During PE tests..." (e.g., "During PE tests, I believe that I have the resources to get a good grade”).

Finally, in cases where some items did not survive the factorial analyses, several items were added to each subscale to ensure a degree of redundancy. Following the procedure of Weiss et al. (2014), the elaboration of the supplementary items was based 
on the conceptual nature of the worry, self-focus, bodily symptoms, somatic tension, perceived control subscales, and a corresponding literature review. This elaboration was also based on Barkoukis et al.'s (2012) recommendations, with an expert panel composed of three researchers specialized in anxiety research, test anxiety research, questionnaire construction, and PE teacher training. Moreover, in accordance with Wren and Benson's (2004) procedure for the construction of a questionnaire assessing test anxiety in young children, a panel of three PE teachers with several years' teaching experience also judged the items. The content-representativeness of the items was evaluated by teachers who were familiar with observing the behaviors of PE students during tests or exams.

At the end of the process, a pool of 37 items was created: 10 items were retained for the worry subscale, eight for the self-focus subscale, six for the bodily symptoms subscale, five for somatic tension subscale, and eight for the perceived control subscale. As in the initial RTA scale (Benson \& El-Zahhar, 1994), students responded to the items on a 4-point scale (almost never to almost always) for the PE version. This choice allows further comparison with results found in the general test anxiety literature.

\section{Results}

Preliminary results. In order to select the most relevant items of the preliminary version of the scale, a Confirmatory Factor Analysis (CFA) was conducted on the covariance matrix of the 37 items using the Lisrel 9.1 program, and the solution was generated using maximum likelihood estimation. CFA was used in the first study rather than Exploratory Factor Analysis (EFA), because the questionnaire adapted in the PE context is based both on theory and on the questionnaire previously validated in the academic domain (RTA; Benson \& Et-Zahhar, 1994). For each of the five factors of the preliminary scale we selected the items that showed the higher standardized factor 
loadings for the CFA. This CFA showed that the standardized factor loadings ranged from .24 to .93 . Some items were subsequently discarded based upon their lower standardized factor loadings compared with those of the other items from the same subscale (e.g., the items removed from the worry subscale; see Table 1). Following the procedure of Wren and Benson (2004), the CFA results also indicated that the modeldata fit could be slightly improved if several items were removed. Finally, we reduced the number of items so that the questionnaire could be completed quickly in future studies during PE classes, without occurrences of inattention or weariness, and without disturbing the PE lesson too much.

Final editing of the items led to a 19 -item version of the scale. Three of the four selected items of the self-focus factor were based on the same definition of self-focus (i.e., how others judge my performance during PE evaluations), whereas the fourth was based on a different definition (i.e., the tendency to denigrate one's own performance). Moreover, the fourth item had a factor loading of .57, which was clearly lower than the factor loadings of the first three items, which ranged between .91 and .93 (see Table 1). Consequently, this reduced 19-item scale was retained with respectively four items on the worry, bodily symptoms, somatic tension and perceived control subscales, and three items on the self-focus subscale (see Table 1). The 19-item scale with five subscales was then used to test the theoretical model of interest, called the Revised Test Anxiety and Regulatory Dimension of Anxiety in Physical Education (RTAR-PE) scale.

Factorial structure of the final RTAR-PE scale. A CFA was conducted on the covariance matrix of the selected items using the Lisrel 9.1 program, and the solution was also generated using maximum likelihood estimation. The fit indices were the comparative fit index (CFI), the incremental fit index (IFI), the standardized root mean square residual (SRMR), and the root mean square error of approximation (RMSEA). 
Following Byrne's (2010) recommendations, $\mathrm{CFI} \geq .95, \mathrm{IFI} \geq .95$, and RMSEA $\leq .05$ were the criteria for a good fitting model and CFI $\geq .90$, IFI $\geq .90$, and RMSEA $\leq .08$ were the criteria for an acceptable fitting model. Concerning SRMR, a value less than .08 is generally considered a good fit (Hu \& Bentler, 1999). The results of the CFA supported the hypothesized five-factor structure of the 19-item scale. The standardized factor loadings ranged from .56 to .86 , with 12 out of 19 items (63.2\%) obtaining a loading higher than .70. In line with Byrne's (2010) and Hu and Bentler's (1999) recommendations, the fit statistics met the criteria for an acceptable fitting model: $\chi^{2}(142, N=281)=292.08, p<.001, \mathrm{CFI}=.98, \mathrm{IFI}=.98, \mathrm{SRMR}=.06$, and $\mathrm{RMSEA}=$ .06. Moreover, levels of internal consistency observed for the five subscales were considered satisfactory. Cronbach's $\alpha$ were all above .70 (Nunnally \& Bernstein, 1994), ranging from .75 to .89 . Worry, self-focus, bodily symptoms, and somatic tension were positively interrelated $(p<.001)$, whereas they were all negatively related to perceived control $(p<.001)$. All the results are summarized in Table 1.

Gender differences. A one-way MANOVA revealed a significant effect of gender on the measured variables $(F(5,267)=14.388$; lambda $=.79, p<.001)$. Several consecutive one-way ANOVAs and Newman-Keuls tests showed that worry, self-focus, bodily symptoms, and somatic tension were higher for girls than for boys $(p<.001, p<$ $.001, p<.05$, and $p<.01$ respectively), whereas perceived control was higher for boys than for girls $(p<.001)$.

The results will be discussed in the discussion section of the article. Because the data analysis of Study 1 was conducted on the 37-item scale, the RTAR-PE needed to be tested directly in its 19 -item version to study its psychometric properties once more. Finally, its convergent, discriminant, and predictive validity also need to be tested.

\section{Please insert Table 1 about here}




\section{Study 2}

The aims of Study 2 were (a) to test the factorial structure of the 19-item version of the RTAR-PE scale on a new sample of students, evidencing potential gender differences, (b) to study its convergent validity and its discriminant validity, and (c) to study its predictive validity with constructs known to be associated with test anxiety and/or PE anxiety, such as achievement goals, interest for PE, perceived competence, effort, and tension in PE.

\section{Method}

Participants. A sample of 390 (183 boys, 207 girls; $M_{\text {age }}=15.12$ years, $S D=$ 1.21; age range 13-18) students from several French collège (ages 13-15, 179 students, $38.55 \%$ girls) and lycées (ages 15-18, 211 students, 52.61\% girls) in the south of France voluntarily participated in the study.

Procedure and measures. Procedure and ethical guarantees were the same as those of Study 1. Participants completed a questionnaire package containing the focal construct and additional scales measuring achievement goals, interest, perceived competence, effort, and tension in PE.

Test anxiety. The questionnaire developed in Study 1 (RTAR-PE scale) was used to assess participants' test anxiety in the PE domain. Participants responded to the items assessing worry (e.g., "During PE tests, I am afraid of failure”), self-focus (e.g., "During PE tests, I am conscious that other students will judge my performance negatively”), bodily symptoms (e.g., "During PE tests, my heart beats more strongly than during PE lessons"), somatic tension (e.g., "During PE tests, I am more nervous than during PE lessons"), and perceived control (e.g., "During PE tests, I believe that I can get a good grade”) on a 4-point scale from almost never to almost always. Factorial structure and internal consistency were again tested on the new sample. 
Interest, perceived competence, effort, and tension in PE. These variables were measured by a French version of the Intrinsic Motivation Inventory (Durand, Cury, Sarrazin, \& Famose, 1996) initially developed to measure intrinsic motivation in sport tasks, and previously used in the PE context with satisfactory internal consistency (e.g., Goudas \& Biddle, 1994). For the present study, "Sport" was changed to "Physical Education" in the whole questionnaire. Students responded to the items assessing interest (e.g., "I enjoy PE”), perceived competence (e.g., "I think I am pretty good in PE”), effort (e.g., "I am working hard during PE lessons”), and tension (e.g., "I feel tense during PE lessons") in PE on a 1 (strongly disagree) to 5 (strongly agree) scale. Internal consistencies were satisfactory for interest $(\alpha=.83)$, perceived competence $(\alpha=$ $.70)$, effort $(\alpha=.73)$, and nearly acceptable for tension $(\alpha=.69)$.

Achievement goals in PE. Achievement goals were assessed with the French Achievement Goals Questionnaire for Sport (Riou et al., 2012), validated in the PE context. Participants responded to the items assessing mastery-approach goals (e.g., "My goal is to improve as much as possible”), mastery-avoidance goals (e.g., "My goal is to avoid making mistakes"), performance-approach goals (e.g., "My goal is to perform better than others"), and performance-avoidance goals (e.g., "I am striving to avoid being inferior to others") on a 1 (strongly disagree) to 5 (strongly agree) scale. Internal consistencies were satisfactory for mastery-approach $(\alpha=.86)$, masteryavoidance $(\alpha=.80)$, performance-approach $(\alpha=.93)$, and performance-avoidance $(\alpha=$ .79) goals.

\section{Results}

Factorial structure. The results of the CFA conducted in Study 2 again supported the hypothesized five-factor structure of the RTAR-PE scale. The fit statistics met the criteria for an acceptable fitting model: $\chi^{2}(142, N=390)=381.80, p<.001$, 
$\mathrm{CFI}=.98, \mathrm{IFI}=.98, \mathrm{SRMR}=.05, \mathrm{RMSEA}=.07$. A satisfactory level of internal consistency was found for each subscale. Cronbach's $\alpha$ were all above .70, ranging from .78 to .92 . Worry, self-focus, bodily symptoms, and somatic tension were positively interrelated $(p<.001)$, whereas they were all negatively related to perceived control $(p<.001)$. All the results are presented in Table 1 .

Gender differences. As in Study 1, a one-way MANOVA revealed a significant effect for gender on the measured variables $(F(5,384)=13.050$, lambda $=.85, p<$ .001). Several consecutive one-way ANOVAs and Newman-Keuls tests showed that worry, self-focus, bodily symptoms, and somatic tension were higher for girls than for boys ( $p<.001, p<.001, p<.01$, and $p<.001$ respectively), whereas perceived control was higher for boys than for girls $(p<.001)$.

Convergent validity. Three procedures are used to assess for convergent validity (Hair, Black, Babin, Anderson, \& Tatham, 2006). First, the item reliability of each measure is considered significant if its factor loading is higher than .50. This is the case for all the items of the scale tested in this study (see Table 1). The standardized factor loadings ranged from .62 to .92 , with 15 out of 19 items (78.9\%) obtaining a loading higher than .70. Secondly, composite reliability focuses on the tendency of Cronbach's $\alpha$ to understate reliability and a value greater than .70 is recommended. As seen in Table 1, composite reliability ranged from .78 to .92 for the five factors of the RTAR-PE scale. Thirdly, the amount of variance captured by the construct in relation to the one error attributable to measurement is represented by the average variance extracted (AVE). Convergent validity is validated if AVE is higher than .50 of the total variance. As seen in Table 1, AVE was acceptable for four of the five factors of the scale (ranging from .58 to .80 ) and was slightly smaller for the worry dimension (.47). 
Discriminant validity. The extent to which the constructs differ is assessed by discriminant validity. A latent correlation matrix is created, and the diagonal elements are replaced by $\sqrt{\mathrm{AVE}}$. If $\sqrt{\mathrm{AVE}}$ for each factor is higher than the correlations between the factor and other factors in the model, the items can be said to be independent of one another (Teo, Lee, Chai, \& Wong, 2009). Discriminant validity was found satisfactory for all factors of the RTAR-PE scale (see Table 1). This result evidenced that each factor shares more variance with its items than it does with other factors.

Predictive validity. Two consecutive hierarchical regression analyses were conducted to assess the predictive validity of the RTAR-PE scale. First, a hierarchical regression analysis was conducted to examine how gender (girls $=0$, boys $=1$ ), interest for PE, perceived competence in PE, tension in PE, and achievement goals in PE were predictors of the different components of test anxiety in PE. Gender was entered in Step 1 to control this variable. The other independent variables were entered into the regression in Step 2. The results showed that worry was negatively predicted by gender, perceived competence, and approach-based goals, and positively predicted by tension and mastery-avoidance goals. Self-focus was negatively predicted by gender, perceived competence, and approach-based goals, and positively predicted by tension and performance-avoidance goals. Bodily symptoms were negatively predicted by masteryapproach goals and positively predicted by tension. Somatic tension was negatively predicted by performance-approach goals and positively predicted by tension and performance-avoidance goals. Finally, perceived control was negatively predicted by tension, and positively predicted by interest, perceived competence, and approach-based goals. The strongest prediction was found for tension in PE, positively predicting somatic tension during tests, while the weakest significant prediction was found for interest in PE, positively predicting perceived control during tests. The detailed results 
are presented in Table 2. Second, another hierarchical regression analysis was conducted to examine how the different components of test anxiety in PE were predictors of effort in PE. Gender was entered in Step 1 and the different components of test anxiety were entered in Step 2. The results first showed that gender was a positive predictor of effort. Moreover, worry and perceived control were found to be positive predictors of effort $(\beta=.15, p<.05$, and $\beta=.33, p<.001$, respectively).

\section{Please insert Table 2 about here}

Complementary analyses. Data from Study 1 and Study 2 were compiled to provide an overview of the whole sample responding to the 19-item RTAR-PE questionnaire. The results of the CFA conducted with the whole sample supported the hypothesized five-factor structure of the RTAR-PE scale. The fit statistics met the criteria for a good fitting model: $\chi^{2}(142, N=671)=394.47, p<.001, \mathrm{CFI}=$ $.98, \mathrm{IFI}=.98, \mathrm{SRMR}=.04$, and $\mathrm{RMSEA}=.05$. This CFA showed that the standardized factor loadings ranged from .62 to .94 . A satisfactory level of internal consistency was found for each subscale. Cronbach's $\alpha$ were all above .70 , ranging from .78 to .91 . Worry, self-focus, bodily symptoms, and somatic tension were positively interrelated $(p<.001)$, whereas they were all negatively related to perceived control $(p<.001)$. All the results are presented in Table 1 .

\section{Discussion}

The present research is the first application of the test anxiety model to the PE domain. Based on the RTA scale (Benson \& El-Zahhar, 1994) and the threedimensional model of performance anxiety (Cheng et al., 2009), Study 1 produced a set of items, showed that the data supported the hypothesized five-factor structure of the RTAR-PE scale, and indicated that each of the five factors had good internal consistency. Study 2 confirmed and reinforced with convergent and discriminant 
validity the psychometric properties of the RTAR-PE scale, and showed the predictive validity of the scale using other constructs that are central in the test anxiety and/or PE anxiety literature (achievement goals, interest, perceived competence, effort, tension).

Regarding the cognitive and somatic components of anxiety, this work necessarily led us to adapt the initial scales assessing test anxiety to the specificities of PE. Three types of adaptation were conducted: (a) bodily symptoms and somatic tension items were reworded, (b) the regulatory dimension of anxiety represented by perceived control was added to the questionnaire, and (c) the self-focus factor was introduced into the scale. The positive intercorrelations between worry, bodily symptoms, and somatic tension related to PE tests are in line with those found in previous research on general test anxiety (e.g., Putwain \& Symes, 2012). The new factor called self-focus which replaced the factor of the initial RTA called test-irrelevant thinking is also positively correlated with worry. This relationship is consistent with the theoretical framework of anxiety because self-focus and test-irrelevant thinking are two different facets of cognitive anxiety. Moreover, worry and self-focus were highly correlated and the correlation between self-focus and perceived control was also negative in Cheng et al.'s (2009) three-dimensional model of performance anxiety. Worry, bodily symptoms, and somatic tension during PE tests were negatively related to perceived control. This is in line with the results of Cheng and Hardy (2016) because perceived control represents an adaptive potential of anxiety whereas the cognitive and emotionality dimensions of anxiety are considered unpleasant states. Finally, the results evidencing that worry, selffocus, bodily symptoms, and somatic tension were higher for girls than for boys are consistent with the literature, in which girls have higher test anxiety than boys (Putwain Woods, et al., 2010). This is also the case in the PE context. 
The predictive validity of the scale was also tested in the present study, first with achievement goals. Worry, self-focus, and somatic tension caused by test anxiety in PE were positively predicted by avoidance-based goals because these components are negative affects and avoidance-based goals are also negatively valenced goals (Elliot \& McGregor, 2001). A similar pattern of results was found by Putwain and Symes (2012) for test anxiety in general. The addition of a new subscale (self-focus) in the RTAR-PE scale is validated by the fact that performance-avoidance goals positively predicted selffocus because they share the same theoretical origins. Self-focus is the fear of the judgment of others on test performance in PE and performance-avoidance goals are focused on not doing poorly relative to others (Mascret et al., 2015).

Concerning perceived competence, our results showed that worry and self-focus were negatively predicted by perceived competence, whereas perceived control was positively predicted. This is consistent with the literature, in which a perception of low competence is related to higher test anxiety because the likelihood of failure increases when the evaluative situation is appraised as more threatening (Putwain \& Symes, 2012). Tension, interest, and effort in PE have not hitherto been studied in relation with test anxiety. In the present study, tension in PE positively predicted worry, self-focus, bodily symptoms, and somatic tension during examinations, and negatively predicted perceived control. Logically, because they have low perceived competence in PE or because they are regularly hampered by the gaze of others, students who feel tense during PE lessons are more likely to have high test anxiety or low perceived control during tests. The pattern is opposite for interest for PE, which is the students' interest in and enjoyment of a course for its own sake. Enjoyment during PE lessons was negatively related to state anxiety in PE (Yli-Piipari et al., 2009), which leads us to believe that there may be the same relationships between interest for PE and the 
negative dimensions of test anxiety in the specific context of PE examinations. This was not the case in the present study. Interest was found to be a positive predictor only of perceived control. Although interest is a strong motivator in PE (Chen \& Wang, 2017), students' interest in PE did not influence the four negative components of test anxiety. Finally, effort was positively predicted by both worry and perceived control. This result indicates that a negative component (worry) and a positive component (perceived control) of test anxiety may induce effort in PE among students to successfully pass the test. According to processing efficiency theory (Eysenck \& Calvo, 1992), the control system involved in anxiety plans and regulates the use of processing resources, and consequently performance may be sustained or even increased due to allocation of additional resources to the test (e.g., effort) despite the negative components of test anxiety (Cheng et al., 2009).

Our research is not without limitations. First, the RTAR-PE scale is based on test anxiety in PE classes. But sport activities are various and it is possible that some sport activities lead to more test anxiety than others. For example, artistic gymnastics or dance always take place in front of spectators, and this may strengthen test anxiety and especially the self-focus subcomponent. Test anxiety may be higher in team sports than individual sports because of the immediate judgment of more numerous teammates and opponents. The risk of injury may induce higher levels of test anxiety in high-risk sports (e.g., climbing) than in lower-risk sports. But test anxiety has been conceptualized as a trait (Spielberger \& Vagg, 1995) and complementary studies should be conducted to show whether the pattern is similar for test anxiety in PE. Secondly, the reliability of the instrument over time was not examined by a test-retest procedure. Thirdly, the present research focused on a sample covering students aged 13-18 and took place in a single country (France). Additional research is needed to examine the generalizability of the 
results in other countries and with younger students, because developmental differences lead researchers to develop age-specific instruments for measuring children's test anxiety (Wren \& Benson, 2004). Fourthly, testing in PE may take a variety of forms, including physical and cognitive testing. Tests of cognitive performance (e.g., taking a quiz on the rules of tennis) or affective performance (e.g., demonstrating appropriate ethical behavior during a small-sided game of basketball) may also be conducted in PE. The RTAR-PE scale deliberately focused on motor performance during tests because on the one hand this kind of cognitive and affective testing does not exist in the French PE context and on the other hand it may be assessed by existing test anxiety scales related to the cognitive and affective domains (e.g., RTA, Benson \& El-Zahhar, 1994; TAI, Spielberger, 1980).

The RTAR-PE scale may have theoretical, research, and practical implications. Theoretically, the literature on test anxiety in the PE context has hitherto been nonexistent. The development of this specific scale confirmed some results from the general test anxiety literature (e.g., the positive correlations between the cognitive and affectivephysiological components of test anxiety), but also evidenced the need to use some constructs related to the specificities of each school subject (e.g., the introduction of the self-focus subscale for PE test anxiety).

From a research point of view, the RTAR-PE is a new scale assessing test anxiety in PE which is now available to develop research in this area. Although in the present study the five factors of the RTAR-PE scale were significantly related to several constructs known to be associated with test anxiety and/or PE anxiety in previous findings, many other variables may be examined to expand this framework. For example, Flanagan, Putwain, and Caltabiano (2015) have studied test anxiety in relation to the 3 x 2 model of achievement goals (self-, task- and other-referenced goals along an 
approach-avoidance dimension). Since a similar measure exists in the sport domain (Mascret et al., 2015), test anxiety in PE may be related to the six factors of the $3 \times 2$ Achievement Goals Questionnaire for Sport to refine the findings of the present study by separating mastery-based goals into task-based and self-based categories (performance relative to the absolute demands of the task or activity and performance relative to one's own trajectory). Studies investigating test anxiety in ecological conditions during PE tests according to the motivational climate effectively implemented by the PE teachers (Harwood, Keegan, Smith, \& Raine, 2015) could also be regarded as promising more applied perspectives.

Finally, practical implications of this scale may be identified. Teachers or school administrators may assess PE test anxiety at the beginning of a school year on the one hand to identify students at risk in a class and on the other hand to take appropriate preventive measures (e.g., increasing students' perceived competence, which was identified in the present study as a negative predictor of worry and self-focus). Testing the effects of a teacher training program on the reduction of PE test anxiety may be a promising direction for future research in this domain.

\section{Conclusion}

Research on test anxiety has been conducted over the past 50 plus years and has been an important focus of research on anxiety literature, resulting in a deeper and broader understanding of the test anxiety construct and its implications in the educational context. The development of scales more adapted to the specificities of each school discipline represents a logical extension of the test anxiety measures. More research on test anxiety in PE is needed for a better understanding of the processes of test anxiety involved in this specific school discipline, to enhance students' motivation for PE, and to create an interest in out-of-school physical activity and active lifestyles to 
preserve or develop students' and future adults' health. 


\section{References}

Barkoukis, V., Rodafinos, A., Koidou, E., \& Tsorbatzoudis, H. (2012). Development of a scale measuring trait anxiety in physical education. Measurement in Physical Education and Exercise Science, 16, 237-253.

doi:10.1080/1091367X.2012.716724

Barkoukis, V., Tsorbatzoudis, H., Grouios, G., \& Rodafinos, A. (2005). The development of a physical education state anxiety scale: A preliminary study. Perceptual and Motor Skills, 100(1), 118-128. doi:10.2466/PMS.100.1.118-128

Benson, J., \& El-Zahhar, N. (1994). Further refinement and validation of the Revised Test Anxiety Scale with cross-validation. Structural Equation Modelling, 1(3), 203-221. doi:10.1080/ 10705519409539975

Byrne, B. M. (2010). Structural equation modelling with AMOS: Basic concepts, applications, and programming. New York, NY: Routledge.

Cassady, J. C., \& Johnson, R. E. (2002). Cognitive test anxiety and academic performance. Contemporary Educational Psychology, 27, 270-295. doi:10.1006/ceps.2001.1094

Chen, A., \& Wang, Y. (2017). The role of interest in physical education: A review of research evidence. Journal of Teaching in Physical Education, 36, 313-322. doi:10.1123/jtpe.2017-0033

Cheng, W. N. K., \& Hardy, L. (2016). Three-dimensional model of performance anxiety: Tests of the adaptive potential of the regulatory dimension of anxiety. Psychology of Sport and Exercise, 22, 255-263. doi:10.1016/j.psychsport.2015.07.006

Cheng, W. N. K., Hardy, L., \& Markland, D. (2009). Toward a three-dimensional conceptualization of performance anxiety: Rationale and initial measurement development. Psychology of Sport and Exercise, 10, 271-278. doi:10.1016/j.psychsport.2008.08.001

Durand, M., Cury, F., Sarrazin, P., \& Famose, J. P. (1996). French version of the Robert-Balague perception of success questionnaire. International Journal of Sport Psychology, 27, 251-268.

Elliot, A. J., \& McGregor, H. A. (2001). A 2 X 2 achievement goal framework. Journal of Personality and Social Psychology, 80, 501-519. doi:10.1037//00223514.80.3.501 
Eysenck, M. W., \& Calvo, M. G. (1992). Anxiety and performance: The processing efficiency theory. Cognition \& Emotion, 6, 409-434. doi:10.1080/02699939208409696

Flanagan, M. J., Putwain, D. W., \& Caltabiano, M. L. (2015). The relationship between goal setting and students' experience of academic test anxiety. International Journal of School \& Educational Psychology, 3, 189-201. doi:10.1080/21683603.2015.1060910

Goudas, M., \& Biddle, S. (1994). Perceived motivational climate and intrinsic motivation in school physical education classes. European Journal of Psychology of Education, 9, 241-250. doi:10.1007/bf03172783

Hagtvet, K. A., \& Benson, J. (1997). The motive to avoid failure and test anxiety responses: Empirical support for integration of two research traditions. Anxiety, Stress, \& Coping, 10, 35-57. doi:10.1080/10615809708249294

Hair, J. F., Jr., Black, W. C., Babin, B. J., Anderson, R. E., \& Tatham, R. L. (2006). Multivariate data analysis (6th ed.). New Jersey: Prentice-Hall International.

Harwood, C. G., Keegan, R. J., Smith, J. M., \& Raine, A. S. (2015). A systematic review of the intrapersonal correlates of motivational climate perceptions in sport and physical activity. Psychology of Sport and Exercise, 18, 9-25. doi:10.1016/j.psychsport.2014.11.005

Hu, L. T., \& Bentler, P. M. (1999). Cutoff criteria for fit indexes in covariance structure analysis: Conventional criteria versus new alternatives. Structural Equation Modeling: A Multidisciplinary Journal, 6(1), 1-55. doi:10.1080/10705519909540118

Liebert, R. M., \& Morris, L. W. (1967). Cognitive and emotional components of test anxiety: A distinction and some initial data. Psychological Reports, 20, 975-978. doi:10.2466/pr0.1967.20.3.975

Liukkonen, J., Barkoukis, V., Watt, A., \& Jaakkola, T. (2010). Motivational climate and students' emotional experiences and effort in physical education. The Journal of Educational Research, 103, 295-308. doi:10.1080/00220670903383044

Mascret, N., Elliot, A. J., \& Cury, F. (2015). Extending the $3 \times 2$ achievement goal model to the sport domain: the $3 \times 2$ achievement goal questionnaire for sport. Psychology of Sport and Exercise, 17, 7-14. doi:10.1016/j.psychsport.2014.11.001 
Meece, J., Wigfield, A., \& Eccles, J. (1990). Predictors of math anxiety and its influence on young adolescents' course enrollment intentions performance in mathematics. Journal of Educational Psychology, 82, 60-70. doi:10.1037/00220663.82.1.60

Nunnally, J.C., \& Bernstein, I.H. (1994). Psychometric theory (3rd ed.). New York, NY: McGraw-Hill.

Ommundsen, Y. (2001). Self-handicapping strategies in physical education classes: The influence of implicit theories of the nature of ability and achievement goal orientations. Psychology of Sport and Exercise, 2, 139-156. doi:10.1016/s14690292(00)00019-4

Putwain, D. W., Connors, L., \& Symes, W. (2010). Do cognitive distortions mediate the test anxiety-examination performance relationship? Educational Psychology, 30, 11-26. doi:10.1080/01443410903328866

Putwain, D. W., \& Symes, W. (2012). Achievement goals as mediators of the relationship between competence beliefs and test anxiety. British Journal of Educational Psychology, 82, 207-224. doi:10.1111/j.2044-8279.2011.02021.x

Putwain, D. W., Woods, K. A., \& Symes, W. (2010). Personal and situational predictors of test anxiety of students in post-compulsory education. British Journal of Educational Psychology, 80(1), 137-160. doi:10.1348/00709909X466082

Riou, F., Boiché, J., Doron, J., Romain, A. J., Corrion, K., Ninot, G., ..., \& Gernigon, C. (2012). Development and validation of the French achievement goals questionnaire for sport and exercise (FAGQSE). European Journal of Psychological Assessment, 28, 313-320. doi:10.1027/1015-5759/a000112

Sanchez-Herrero, S., \& Sanchez, M. (1992). The predictive validation of an instrument designed to measure student anxiety in learning a foreign language. Educational and Psychological Measurement, 52, 961-966.

Sarason, I. G. (1961). Test anxiety and the intellectual performance of college students. Journal of Educational Psychology, 52, 201-206. doi:10.1037/h0049095

Sarason, I. G. (1984). Stress, anxiety, and cognitive interference: Reactions to tests. Journal of Personality and Social Psychology, 46, 929-938. doi:10.1037/00223514.46.4.929

Siegel, J. M., Yancey, A. K., Aneshensel, C. S., \& Schuler, R. (1999). Body image, perceived pubertal timing, and adolescent mental health. Journal of Adolescent Health, 25, 155-165. doi:10.1016/S1054-139X(98)00160-8 
Smith, R., Schutz, R., Smoll, F., \& Ptacek, J. T. (1995). Development and validation of a multidimensional measure of sport-specific psychological skills: The Athletic Coping Skills Inventory-28. Journal of Sport and Exercise Psychology, 17, 379398. doi:doi.org/10.1123/jsep.17.4.379

Spielberger, C.D. (1980). Preliminary professional manual for the test anxiety inventory. Palo Alto, CA: Consulting Psychologists Press.

Spielberger, C. D., \& Vagg, P. R. (1995). Test anxiety: A transactional process model. In C. D. Speilberger \& P. R. Vagg (Eds.), Test anxiety: Theory, assessment, and treatment (pp. 3-14). Bristol, PA: Taylor \& Frances.

Teo, T., Lee, C. B., Chai, C. S., \& Wong, S. L. (2009). Assessing the intention to use technology among pre-service teachers in Singapore and Malaysia: A multigroup invariance analysis of the Technology Acceptance Model (TAM). Computers \& Education, 53, 1000-1009. doi:10.1016/j.compedu.2009.05.017

Walling, M. D., \& Duda, J. L. (1995). Goals and their associations with beliefs about success in and perceptions of the purposes of physical education. Journal of Teaching in Physical Education, 14, 140-156. doi:10.1123/jtpe.14.2.140

Warburton, V. E. (2017). Peer and teacher influences on the motivational climate in physical education: A longitudinal perspective on achievement goal adoption. Contemporary Educational Psychology, 51, 303-314. doi:10.1016/j.cedpsych.2017.08.001

Warburton, V. E., \& Spray, C. M. (2017). Implicit theories of ability in physical education: Current issues and future directions. Journal of Teaching in Physical Education, 36, 252-261. doi:10.1123/jtpe.2017-0043

Weiss, M. R., Bolter, N. D., \& Kipp, L. E. (2014). Assessing impact of physical activity-based youth development programs: Validation of the Life Skills Transfer Survey. Research Quarterly for Exercise and Sport, 85, 263-278. doi:10.1080/02701367.2014.931558

Wren D. G., \& Benson J. (2004). Measuring test anxiety in children: Scale development and internal construct validation. Anxiety, Stress, \& Coping, 17, 227-240. doi:10.1080/10615800412331292606

Yli-Piipari, S., Watt, A., Jaakkola, T., Liukkonen, J., \& Nurmi, J. E. (2009). Relationships between physical education students' motivational profiles, enjoyment, state anxiety, and self-reported physical activity. Journal of Sports Science and Medicine, 8, 327-336. 
Zeidner, M. (2007). Test anxiety in educational contexts. In P. A. Schutz \& R. Pekrun (Eds.), Emotion in education (pp. 165-184). Burlington, MA: Elsevier. 
Table 1

Standardized factor loading, descriptive statistics, internal consistencies, intercorrelations

(Study 1, Study 2, whole sample), construct reliability, average variance extracted, and discriminant validity (Study 2).

\begin{tabular}{|c|c|c|c|c|c|c|c|c|c|}
\hline \multicolumn{5}{|l|}{ Factors/Items } & $\begin{array}{l}\text { SFL } \\
\text { (St1) } \\
\end{array}$ & $\begin{array}{l}\text { SFL } \\
\text { (St2) }\end{array}$ & $\begin{array}{l}\text { SFL } \\
\text { (WS) }\end{array}$ & $\begin{array}{c}\text { CR } \\
\text { (St2) }\end{array}$ & $\begin{array}{l}\text { AVE } \\
\text { (St2) }\end{array}$ \\
\hline \multicolumn{5}{|c|}{ Factor 1: Worry } & & & & .78 & .47 \\
\hline \multicolumn{5}{|c|}{ I often think about how difficult it is } & .76 & .62 & .68 & & \\
\hline \multicolumn{5}{|c|}{ I am afraid of failure } & .56 & .76 & .64 & & \\
\hline \multicolumn{5}{|c|}{ I am afraid of having a lower performance than during PE lessons } & .86 & .68 & .74 & & \\
\hline \multicolumn{5}{|c|}{ I often think that other students are better than me } & .76 & .68 & .62 & & \\
\hline \multicolumn{5}{|c|}{ *Thinking about the grade that I may have interferes with my work } & .37 & - & - & & \\
\hline \multicolumn{5}{|c|}{ *I have the impression of breaking down } & .54 & - & - & & \\
\hline \multicolumn{5}{|c|}{ *I often think about the consequences of failure } & .54 & - & - & & \\
\hline \multicolumn{5}{|c|}{ *I often think about how I should have prepared myself } & .43 & - & - & & \\
\hline \multicolumn{5}{|c|}{$*$ I am afraid of injuring myself } & .36 & - & - & & \\
\hline \multicolumn{5}{|c|}{ *I am afraid of making mistakes } & .35 & - & - & & \\
\hline \multicolumn{5}{|c|}{ Factor 2: Self-focus } & & & & .92 & .80 \\
\hline \multicolumn{5}{|c|}{ I am conscious that other students will judge my performance negatively } & .93 & .86 & .92 & & \\
\hline \multicolumn{5}{|c|}{ I think that other students may criticize my performance } & .91 & .92 & .94 & & \\
\hline \multicolumn{5}{|c|}{ I am conscious that other students will mock my performance } & .92 & .90 & .91 & & \\
\hline \multicolumn{5}{|c|}{ *I have a tendency to focus on my faults } & .43 & - & - & & \\
\hline *I assess myself seve & & & & & .24 & - & - & & \\
\hline *I think about the po & ity of a bad $g$ & & & & .56 & - & - & & \\
\hline *I have a tendency t & igrate my per & rmance & & & .57 & - & - & & \\
\hline Factor 3: Bodily symp & & & & & & & & .85 & .58 \\
\hline I find myself trembli & ore than durin & PE lessons & & & .53 & .75 & .67 & & \\
\hline My heart beats harde & $\mathrm{h}$ during PE le & sons & & & .58 & .80 & .62 & & \\
\hline I have more difficult & athing than $\mathrm{du}$ & ng PE lessons & & & .62 & .79 & .75 & & \\
\hline My muscles are tigh & an during PE & ssons & & & .60 & .70 & .68 & & \\
\hline * My hands are mois & an during PE & ssons & & & .48 & - & - & & \\
\hline *My mouth is drier & luring PE less & & & & .46 & - & - & & \\
\hline Factor 4: Somatic tens & & & & & & & & .84 & .58 \\
\hline I feel more tense tha & ing PE lesson & & & & .70 & .68 & .63 & & \\
\hline I feel more anxious $t$ & luring PE less & & & & .65 & .82 & .67 & & \\
\hline I feel more uneasy th & aring PE lesso & & & & .63 & .73 & .66 & & \\
\hline I am more nervous tl & uring $\mathrm{PE}$ less & & & & .70 & .80 & .69 & & \\
\hline *I am more tired tha & ing PE lesson & & & & .25 & - & - & & \\
\hline Factor 5: Perceived co & & & & & & & & .92 & .73 \\
\hline I believe in my capa & get a good g & & & & .81 & .85 & .76 & & \\
\hline I feel ready to get a & grade & & & & .83 & .83 & .80 & & \\
\hline I believe that I have & sources to get & good grade & & & .81 & .85 & .79 & & \\
\hline I believe that I can $g$ & ood grade & & & & .76 & .89 & .80 & & \\
\hline *I am staying focuse & my performar & & & & .22 & - & - & & \\
\hline *I am confident that & get a good gr & & & & .75 & - & - & & \\
\hline *I believe that I will & ccessful & & & & .76 & - & - & & \\
\hline *I know I can get a & grade & & & & .35 & - & - & & \\
\hline St1 / St2 - Variables & M & SD & $\alpha$ & 1 & & 2 & 3 & 4 & 5 \\
\hline 1. Worry & $2.34 / 2.10$ & $0.83 / 0.74$ & $.78 / .78$ & $(.69)$ & & & & & \\
\hline 2. Self-focus & $2.18 / 1.89$ & $1.01 / 0.92$ & $.89 / .92$ & $.83 / .56$ & & $(.89)$ & & & \\
\hline 3. Bodily symptoms & $1.96 / 1.61$ & $0.76 / 0.72$ & $.75 / .84$ & $.41 / .46$ & & $36 / .31$ & $(.76)$ & & \\
\hline 4. Somatic tension & $1.84 / .1 .54$ & $0.77 / 0.68$ & $.78 / .84$ & $.67 / .60$ & & $.57 / .53$ & $.58 / .48$ & $(.76)$ & \\
\hline 5. Perceived control & $2.79 / 2.80$ & $0.85 / 0.82$ & $.89 / .92$ & $-.48 /-.51$ & & $.45 /-.41$ & $-.22 /-.31$ & $-.39 /-.35$ & (.85) \\
\hline WS - Variables & $\mathbf{M}$ & SD & $\alpha$ & 1 & & 2 & 3 & 4 & 5 \\
\hline 1. Worry & 2.20 & 0.79 & .78 & - & & & & & \\
\hline 2. Self-focus & 2.01 & 0.97 & .91 & .62 & & - & & & \\
\hline 3. Bodily symptoms & 1.76 & 0.76 & .80 & .45 & & .34 & - & & \\
\hline 4. Somatic tension & 1.66 & 0.73 & .82 & .63 & & .50 & .51 & - & \\
\hline 5. Perceived control & 2.79 & 0.83 & .90 & -.49 & & -.37 & -.25 & -.35 & - \\
\hline
\end{tabular}

Notes. $\alpha=$ Cronbach's $\alpha, \mathrm{SFL}=$ Standardized Factor Loading, $\mathrm{CR}=$ Composite Reliability, AVE $=$ Average Variance Extracted, St1 $=$ Study

1, St2 = Study 2, WS = Whole Sample, * denotes items that were removed from the CFA conducted in Study 2, all the correlations were 
significant at $p<.001$, means, standard deviations, Cronbach's $\alpha$, and intercorrelations of Study 1 are presented before the slash and those of Study 2 after the slash, the diagonal elements in bold represent $\sqrt{\mathrm{AVE}}$ for Study 2. 
Table 2

Summary of hierarchical regression analyses predicting test anxiety components

\begin{tabular}{|c|c|c|c|c|c|c|c|c|c|c|}
\hline & \multicolumn{2}{|c|}{ Worry } & \multicolumn{2}{|c|}{ Self-focus } & \multicolumn{2}{|c|}{ Bodily symptoms } & \multicolumn{2}{|c|}{ Somatic tension } & \multicolumn{2}{|c|}{ Perceived control } \\
\hline & $R^{2}$ & $\beta$ & $R^{2}$ & $\beta$ & $R^{2}$ & $\beta$ & $R^{2}$ & $\beta$ & $R^{2}$ & $\beta$ \\
\hline Step 1: & $.102 * * *$ & & $.074 * * *$ & & $.025 * *$ & & $.043 * * *$ & & $.107 * * *$ & \\
\hline Gender $^{1}$ & & $-.10 *$ & & $-.14 * *$ & & -.03 & & -.09 & & $.09 *$ \\
\hline Step 2 & $.450 * * *$ & & $.340 * * *$ & & $.196 * * *$ & & $.365 * * *$ & & $.495 * * *$ & \\
\hline Interest & & .03 & & .09 & & -.08 & & -.04 & & $.11 *$ \\
\hline Perceived competence & & $-.23 * * *$ & & $-.18 * *$ & & -.01 & & -.02 & & $.34 * * *$ \\
\hline Tension & & $.38^{* * *}$ & & $.33 * * *$ & & $.31 * * *$ & & $.48 * * *$ & & $-.17 * * *$ \\
\hline Performance-approach goals & & $-.15 * *$ & & $-.17 * *$ & & -.09 & & $-.14 * *$ & & $.16^{* * *}$ \\
\hline Mastery-approach goals & & $-.13 * *$ & & $-.15^{* *}$ & & $-.15^{*}$ & & -.06 & & $.19 * * *$ \\
\hline Performance-avoidance goals & & .10 & & $.20 * * *$ & & -.01 & & $.21 * * *$ & & -.08 \\
\hline Mastery-avoidance goals & & $.14 * *$ & & -.02 & & .09 & & -.07 & & .01 \\
\hline
\end{tabular}

Note. ${ }^{*} p<.05, * * p<.01, * * * p<.001$

${ }^{1}$ The $\beta$ coefficients from the final regression equation 